Repository of the Max Delbrück Center for Molecular Medicine (MDC) Berlin (Germany)

http://edoc.mdc-berlin.de/14020/

\title{
Swelling and mechanical properties of alginate hydrogels with respect to promotion of neural growth
}

Marina Matyash, Florian Despang, Chrysanthy Ikonomidou, and Michael Gelinsky

This is a copy of an article published in Tissue Engineering Part C Methods.

(C) 2014 Mary Ann Liebert, Inc.

Tissue Engineering Part C Methods is available online at: http://online.liebertpub.com. 


\title{
Swelling and Mechanical Properties of Alginate Hydrogels with Respect to Promotion of Neural Growth
}

\author{
Marina Matyash, PhD, , ${ }^{1,2}$ Florian Despang, Dipl-Ing,, Chrysanthy Ikonomidou, MD, PhD, ${ }^{3}$ \\ and Michael Gelinsky, $\mathrm{PhD}^{1}$
}

Soft alginate hydrogels support robust neurite outgrowth, but their rapid disintegration in solutions of high ionic strength restricts them from long-term in vivo applications. Aiming to enhance the mechanical stability of soft alginate hydrogels, we investigated how changes in $\mathrm{pH}$ and ionic strength during gelation influence the swelling, stiffness, and disintegration of a three-dimensional (3D) alginate matrix and its ability to support neurite outgrowth. Hydrogels were generated from dry alginate layers through ionic crosslinks with $\mathrm{Ca}^{2+}$ $(\leq 10 \mathrm{mM})$ in solutions of low or high ionic strength and at $\mathrm{pH} 5.5$ or 7.4. High- and low-viscosity alginates with different molecular compositions demonstrated $\mathrm{pH}$ and ionic strength-independent increases in hydrogel volume with decreases in $\mathrm{Ca}^{2+}$ concentrations from 10 to $2 \mathrm{mM}$. Only soft hydrogels that were synthesized in the presence of $150 \mathrm{mM}$ of $\mathrm{NaCl}$ (Ca-alginate ${ }_{\mathrm{NaCl}}$ ) displayed long-term volume stability in buffered physiological saline, whereas analogous hydrogels generated in $\mathrm{NaCl}$-free conditions (Ca-alginate) collapsed. The stiffnesses of Ca-alginate ${ }_{\mathrm{NaCl}}$ hydrogels elevated from 0.01 to $19 \mathrm{kPa}$ as the $\mathrm{Ca}^{2+}$-concentration was raised from 2 to $10 \mathrm{mM}$; however, only Ca-alginate $\mathrm{NaCl}$ hydrogels with an elastic modulus $\leq 1.5 \mathrm{kPa}$ that were generated with $\leq 4 \mathrm{mM}$ of $\mathrm{Ca}^{2+}$ supported robust neurite outgrowth in primary neuronal cultures. In conclusion, soft Ca-alginate ${ }_{\mathrm{NaCl}}$ hydrogels combine mechanical stability in solutions of high ionic strength with the ability to support neural growth and could be useful as 3D implants for neural regeneration in vivo.

\section{Introduction}

B IOCOMPATIBLE THREE-DiMENSIONAL (3D) scaffolds for neural tissue engineering must provide an adhesive matrix for regenerating cells, be mechanically compatible with elastic neural tissues, and display dimensional stability in the presence of physiological fluids because extensive swelling or shrinking will affect scaffold-tissue unity or compress the surrounding healthy tissues. ${ }^{1,2}$ Hydrogels are 3D networks of interconnected polymer fibers wherein entrapped liquid occupies most of the volume. Hydrogels are permeable to nutrients, support the viability of encapsulated cells, and can incorporate growth factors or other polymers. A variety of natural and synthetic biomaterials form hydrogels.,

Alginate is a biocompatible, natural, linear, binary copolymer composed of D-mannuronic acid (M) and its C5 epimer L-guluronic acid $(\mathrm{G})$ monosaccharide units, which are covalently linked by $\beta-1-4$ glycosidic bonds. $M$ and $G$ are distributed within the polymer chain in varying proportions to produce heterogeneous alternating (MG) and homogeneous (MM or GG) sequences in the primary structure. ${ }^{5-9}$ In aqueous solutions (sols), alginate exists as a negatively charged polyanion that forms a hydrogel by the physical association of polysaccharide chains through ionic crosslinking of $\mathrm{G}$ residues by multivalent cations (e.g., $\mathrm{Ca}^{2+}, \mathrm{Sr}^{2+}$, $\mathrm{Ba}^{2+}, \mathrm{Zn}^{2+}, \mathrm{Cu}^{2+}, \mathrm{Ni}^{2+}$, or $\left.\mathrm{Fe}^{3+}\right)$. This process has been described by the egg-box model in which divalent ions interact with two adjacent $G$ residues and with two $G$ residues of an opposing chain. ${ }^{10,11}$ The density of the alginate fiber network within a hydrogel and its gel strength are regulated by the number of connected gelling sites; as a result, these properties are elevated with an increasing level of crosslinking ion saturation in the alginate and reduced with an increasing number of free G blocks. ${ }^{6,12-14}$

The behavior of charged polyelectrolytes, which includes alginates, is strongly regulated by the $\mathrm{pH}$ and ionic strength of the surrounding solution; $\mathrm{pH}$ controls the degree of dissociation of the guluronic and mannuronic acid groups, while ionic strength triggers the interaction of the resulting negative charges along the polymer chains. ${ }^{15,16}$ Most polyelectrolyte-based gels disintegrate upon immersion in solutions of high ionic strength. Ionically crosslinked alginate hydrogels undergo disintegration in the presence of calcium chelators (e.g., phosphates), monovalent ions (e.g., $\mathrm{Na}^{+}$), and

\footnotetext{
${ }^{1}$ Center for Translational Bone, Joint and Soft Tissue Research, University Hospital and Medical Faculty, Technische Universität Dresden, Dresden, Germany.

${ }^{2}$ Cellular Neuroscience, Max-Delbrück-Center for Molecular Medicine, Berlin, Germany.

${ }^{3}$ Developmental Brain Injury Laboratory, University of Wisconsin, Madison, Wisconsin.
} 
non-cross-linking divalent ions (e.g., $\mathrm{Mg}^{2+}$ ), which are present in the tissue culture medium and tissue fluids. ${ }^{17-19}$ Disintegration of polyelectrolyte-based hydrogels strongly limit their usefulness for in vivo applications, which require long-term 3D stability of the implant. Traditionally, alginate gels were fabricated in $\mathrm{NaCl}$-free solutions; recent studies on gelation speed, swelling, and degradation and on the critical steps in $\mathrm{Ca}^{2+}$ binding to alginates were also performed on hydrogels fabricated in NaCl-free solutions. ${ }^{20-23}$ Conventional methods to stabilize alginate hydrogels include covalent crosslinking and application of high concentrations of crosslinking cations to ensure tight connections between the polymer chains. ${ }^{24-26}$

Physical cues such as substrate stiffness are important factors for cell differentiation and behavior. ${ }^{27,28}$ The successful use of hydrogels greatly relies on the refined control of the mechanical properties, including stiffness. Neurons can sense the stiffness of a substrate and will behave accordingly. For example, soft but not stiff alginate hydrogels support robust neurite outgrowth in vitro. ${ }^{29}$ Dorsal root ganglion neurons display maximal growth on soft substrates with stiffnesses $<1 \mathrm{kPa} .^{30,31}$ Neurons plated on softer substrates showed decreased branching relative to neurons grown on stiffer substrates. ${ }^{32,33}$ Mesenchymal stem cells and primary neural stem cells differentiate into neurons on soft hydrogels with stiffnesses $<1 \mathrm{kPa} .{ }^{34-37}$ Stiff alginate hydrogels were demonstrated to be nonadhesive for neurons; to provide an adhesive surface, these hydrogels required functionalizations with signaling molecules such as laminin and fibronectin ${ }^{38-40}$ and integration of polyglycolic acid, heparin, or basic fibroblast growth factor (bFGF). ${ }^{41-44}$ Anisotropic, stiff alginate scaffolds, which were covered with collagen or polylysine or incorporated gelatin, were shown to support neurite elongation along capillary channels, but prohibited neural ingrowth into the hydrogel core. ${ }^{45,46}$

Soft alginate hydrogels support neural growth, but nothing is yet known about how to enhance their mechanical stability in solutions of high ionic strength without elevation of their stiffness and affecting their interaction with neural cells. This study emphasizes that gelation of alginate layers with substoichiometric concentrations of calcium ions in the presence of $\mathrm{NaCl}$ generates soft Ca-alginate $\mathrm{NaCl}_{\text {hydrogels, }}$ hy which combine mechanical stability with high adhesion to neural cells. This translational research opens a new perspective on the design of stable 3D polyelectrolyte-based hydrogels for long-term in vivo applications.

\section{Materials and Methods}

\section{Materials and reagents}

Ultrapure sodium alginates with trade name PRONOVA were purchased from Novamatrix, now part of FMC BioPolymer, as guluronic acid rich alginate (LVG) and mannuronic acid rich alginate (LVM), and endogen-free S-alginate were purchased from Sigma (71238; Taufkirchen, Germany). The molecular compositions of LVG and LVM were provided by the supplier, but the composition of S-alginate was quantified for this study by a proton ${ }^{1} \mathrm{H}-\mathrm{NMR}$ spectroscopy method. ${ }^{47}$ LVM, LVG, and S-alginates contained $43 \%, 68 \%$, and $68 \%$ guluronic acid residues, respectively. Reagents, including the neurobasal medium, DMEM/F12 (1:1), B-27 supplement, Dulbecco's Phosphate-Buffered Saline without $\mathrm{Ca}^{2+}$ and
$\mathrm{Mg}^{2+}$, and trypsin/EDTA solution were all purchased from Invitrogen (Darmstadt, Germany). $\mathrm{CaCl}_{2}$ dihydrate, HEPES, TRIS, $\mathrm{NaCl}$, and DNase I originated from Sigma.

\section{Preparation of alginate hydrogels at ambient conditions}

Alginates were dissolved in deionized water under permanent stirring at room temperature (RT) for $12 \mathrm{~h}$. The resulting aqueous $0.5 \%, 1.0 \%$, or $1.5 \%$ sols were sterilized by pressing through a $0.45-\mu \mathrm{m}$ sterile filter. Dried alginate layers were formed on glass coverslips $(24 \times 24 \mathrm{~mm})$ when each sol was evenly distributed onto a glass surface and dried at RT for $24 \mathrm{~h}$. Dry alginate layers were stored under humidity-free conditions and used within 10 days after preparation. To form a hydrogel, a glass coverslip with a dry alginate layer was placed into a Petri dish $(\varnothing 5 \mathrm{~cm})$ and overlayed with a $15 \mathrm{~mL}$ crosslinking solution; the gelation reaction was carried out at RT for $24 \mathrm{~h}$, and a single interconnected gel slice was formed on the glass surface. The excess crosslinking solution was removed before gravimetric and rheological analyses. Representative images of hydrogels were taken with a digital camera. For the cell culture experiments, hydrogels were prepared under sterile conditions in a laminar flow hood as described previously. ${ }^{29}$ For rheological characterization, hydrogels were prepared in plastic Petri dishes $(\varnothing 5 \mathrm{~cm})$ from dry alginate layers derived from $1 \%$ alginate sol, and the gelation reaction was carried out at RT for $24 \mathrm{~h}$.

\section{Composition of crosslinking solutions}

Alginate hydrogels were prepared through ionic crosslinking, and an aqueous calcium chloride solution was used as a source of $\mathrm{Ca}^{2+}$ cations. The concentration of $\mathrm{CaCl}_{2}$ in the crosslinking solutions ranged from 0 to $10 \mathrm{mM}$. The $\mathrm{pH}$ values of the crosslinking solutions were adjusted to either 5.5 or 7.4 with the HEPES buffer solution. Some of the crosslinking solutions contained $\mathrm{NaCl}(150 \mathrm{mM}$, final). Our abbreviation scheme describes the characteristics of the hydrogel's ionic composition in the crosslinking solution; for example, Ca-alginate and $\mathrm{Ca}$-alginate $\mathrm{NaCl}_{\mathrm{N}}$ hydrogels were generated with $\mathrm{CaCl}_{2}$ dissolved either in water or in $150 \mathrm{mM}$ $\mathrm{NaCl}$, respectively.

\section{Measurements of alginate hydrogel swelling in gravimetric assay}

The weight of each hydrogel (g) was measured on an analytical balance (Sartorius, Göttingen, Germany; $0.1 \mathrm{mg}$ precision). To preserve gel integrity, the cumulative mass of a glass-gel sandwich was measured and the average weight of the glass coverslips $(0.22 \mathrm{~g})$ was subtracted to obtain the hydrogel's mass. At least three independent samples were prepared for every experimental condition. The Student's t-test for unpaired observations was applied to make a statistical analysis of the data. The rate of swelling was estimated after comparison of the hydrogel mass with the mass of the $1 \%$ alginate sol (taken as $100 \%$ ).

\section{Rheological characterization of alginate sols and hydrogels}

Rheological measurements were carried out using an Anton-Paar Physica MCR301 (Graz, Austria) instrument. The 
viscosity values of aqueous alginate solutions were recorded under continuous logarithmically increasing shear in a double slit chamber DG26.7 at $20^{\circ} \mathrm{C}$. A stress sweep at a constant frequency of $1 \mathrm{~Hz}$ was performed to obtain values for the elastic modulus $\left(G^{\prime}\right)$ of alginate hydrogels. Viscosity values were recorded with the help of a measurement cell with parallel plate geometry (PP25) under logarithmically increasing amplitude $(0.001-100 \mathrm{~Pa})$ at $37^{\circ} \mathrm{C}$. Each hydrogel was transferred onto the measuring device and cut into the shape of a disk $(\varnothing 25 \mathrm{~mm})$. Samples were equilibrated at $37^{\circ} \mathrm{C}$ for $5 \mathrm{~min}$ before measurements.

\section{Culturing of primary neuronal cells}

Neuronal cell cultures were prepared from E20 Wistar rat fetuses. Cells were isolated from cortices as described. ${ }^{48}$ As we reported previously, cleavage of the cell surface molecules during acute brain tissue dissociation using serine protease trypsin alters initiation of neural cell adhesion and growth on soft alginate hydrogels. ${ }^{29}$ Therefore, in the present study, we used primary cell spheroids, which were completely recovered from treatment with trypsin. Primary cells were seeded at an initial cell density of $1 \times 10^{6}$ cells/well in uncovered six-well plates with $2 \mathrm{~mL}$ of expansion medium consisting of DMEM/F-12 (1:1) supplemented with $2 \mathrm{mM}$ Lglutamine, $15 \mathrm{mM}$ HEPES, $20 \mathrm{ng} / \mathrm{mL}$ of rhEGF (Sigma), and $10 \mathrm{ng} / \mathrm{mL}$ of rh-bFGF (Sigma). Subsequently, multiple spheroids formed after reaggregation or/and proliferation of cells on day 3 in vitro. Spheroids were collected, replated onto hydrogel samples, and cultured in a differentiating medium to potentiate differentiation toward neural cells. The differentiating medium consisted of $2 \%$ B-27 supplemented neurobasal medium, $0.5 \mathrm{mM}$ L-glutamine, and 1\% ampicillin and $1 \%$ streptomycin solution. Cell incubation was carried out at $37^{\circ} \mathrm{C}$ in a humidified $95 \%$ air and $5 \% \mathrm{CO}_{2}$ atmosphere.

\section{Immunocytochemistry}

The primary monoclonal mouse antibodies were anti- $\beta$ tubulin III, anti-GFAP, and anti-Tau-1 (from Chemicon, Schwalbach, Germany) and anti-nestin (R\&D Systems, Wiesbaden-Nordenstadt Germany), and secondary antibodies were Alexa Fluor-488 chicken anti-mouse (Molecular Probes/Invitrogen). Labeling with antibodies was performed according to a standard procedure; Hoechst $33342(10 \mu \mathrm{g} / \mathrm{mL}$ in TBS) was used to label the nuclei. Samples were examined under a fluorescence microscope (Axiovert 40; Zeiss, Jena, Germany) and confocal microscope (LSM-710; Zeiss).

\section{Neurite-bearing spheroids, neurite length, and statistical analysis}

Spheroids that were formed from $1 \times 10^{6}$ primary cortical cells were collected into a sterile tube containing a fresh portion $(6 \mathrm{~mL})$ of a differentiating medium, then mixed, and evenly distributed on top of three identical Ca-alginate $\mathrm{NaCl}$ hydrogels (e.g., Ca-alginate $\mathrm{NaCl}_{\mathrm{C}}$ hydrogels derived from Salginate crosslinked with a solution containing $2 \mathrm{mM}$ of $\mathrm{CaCl}_{2}, 150 \mathrm{mM}$ of $\mathrm{NaCl}$, and at $\mathrm{pH} \mathrm{7.4)} \mathrm{and} \mathrm{cultured} \mathrm{sub-}$ sequently for $48 \mathrm{~h}$. The diameter of spheroids ranged from 50 to $250 \mu \mathrm{m}$ by day 5 in vitro. Spheroids that extended 10 or more neurite from at least a quarter of its surface contacting the hydrogel were defined as neurite-bearing spheroids; of note, the vast majority of neurite-bearing spheroids extend 50 or more neurite. Single cells as well as aggregates of cells (2-10 cells) were not considered during spheroid counting. The proportion of neurite-bearing spheroids was quantified after the examination of 50 random live spheroids cultured on top of three identical Ca-alginate ${ }_{\mathrm{NaCl}}$ hydrogels. Different types of hydrogels were derived either from S-alginate, LVG, or LVM alginates crosslinked at pH 5.5 or 7.4 with a solution containing different concentrations of aqueous $\mathrm{CaCl}_{2}$ (i.e., 2, $4,6,8$, or $10 \mathrm{mM}$ ) and $150 \mathrm{mM}$ of $\mathrm{NaCl}$ as described above. In each independent cell culture experiment, 30 different hydrogel types were generated and tested for their ability to support neurite outgrowth. Every hydrogel type was generated in triplicate; subsequently, in each independent cell culture experiment, spheroids were examined on 90 individual hydrogels. The final proportion of neurite-bearing spheroids on every hydrogel type was estimated from two independent cell culture experiments after the examination of 100 (in total) individual spheroids on six identical hydrogels. The distance of neurite extension from spheroids was quantified in two independent cell culture experiments $48 \mathrm{~h}$ after plating of spheroids on top of different types of soft Ca-alginate $\mathrm{NaCl}_{\mathrm{Cl}}$ hydrogels generated using S-alginate, LVG, and LVM with $2 \mathrm{mM}$ of aqueous $\mathrm{CaCl}_{2}$ at $\mathrm{pH} 7.4$ as described above. Subsequently, 20 random spheroids were examined per one type of a hydrogel and the length of 20-50 random neurite per spheroid was quantified on live phase-contrast images (Zeiss Ph2 Plan-NEOFLUAR 20X/0.5 objective, Axiovert 40; Zeiss) using NeuronJ (www .imagescience.org/meijering/software/neuronj). The Student's $t$-test for unpaired observations was applied for statistical analysis. Differences between samples with $p$-value $<0.05$ were accepted as statistically significant.

\section{Results}

\section{Swelling of Ca-alginate hydrogels in aqueous $\mathrm{CaCl}_{2}$ solution}

Swelling is a result of liquid absorption by the polymer, and could be estimated by measuring the hydrogel mass. Dry alginate polysaccharide chains swell in water to produce a sol, but they can swell in the presence of crosslinking di- or multivalent cations, which lead to a hydrogel. Crosslinking of surface-attached dry alginate layers by a $2 \mathrm{mM}$ aqueous $\mathrm{CaCl}_{2}$ solution resulted in the interconnection of polysaccharide molecules and the formation of a single gel slice (soft hydrogel), which support robust neurite outgrowth in vitro; in contrast, gelation of the alginate sol in an aqueous solution under gentle stirring generated multiple gel fragments of irregular size. The appearance of the soft hydrogels (e.g., fragments or slices) did not alter their high adhesiveness to neurite. These results matched our previous data ${ }^{29}$ and demonstrated that dry alginate layers could efficiently form soft hydrogels with the ability to support robust neural growth.

While cultivating neurons on top of soft hydrogels, we often observed variability in the long-term hydrogel stability: some hydrogels disintegrated in the presence of a cell culture medium during the first 3 days, but others persisted for up to 10 weeks and longer. In this study, we generated hydrogels from surface-attached dry layers of different 
alginates and tested how changes of the ionic strength and $\mathrm{pH}$ during the crosslinking influenced mechanical properties of hydrogels. At a constant concentration of calcium $\left(2 \mathrm{mM}\right.$ of $\left.\mathrm{CaCl}_{2}\right), \mathrm{pH} 5.5$ and either in the absence or presence of $\mathrm{NaCl}(150 \mathrm{mM})$ during the crosslinking, the gel mass was proportional to the sol volume (Fig. 1a) and increased linearly with increased alginate concentrations in the sol (Fig. 1b). In the concentration range from $0-10 \mathrm{mM}$ of $\mathrm{CaCl}_{2}$ in the crosslinking solution, the amount of $\mathrm{Ca}^{2+}$ had a nonlinear effect on the growth of a gel mass. A slow linear increase of the hydrogel's mass was correlated with a subsequent decrease in $\mathrm{CaCl}_{2}$ concentration from 10 to $4 \mathrm{mM}$, but a much more rapid increase of hydrogel mass was detected after gelation with $\leq 4 \mathrm{mM}$ of $\mathrm{CaCl}_{2}$. The formation of a single interconnected hydrogel slice was abolished after $\mathrm{Ca}^{2+}$ reached its minimal gel-forming concentration. This swelling profile was observed for S-alginate, LVG, and LVM (Fig. 2). Moreover, the minimal gel-forming concentration of $\mathrm{CaCl}_{2}$ decreased with an increase of G-content in the alginate, and the level was found to be $0.8 \pm 0.2,1.0 \pm 0.2$, and $2.0 \pm 0.2 \mathrm{mM}$ for S-alginate, LVG, and LVM, respectively (Fig. 2). In the presence of substoichiometric concentrations of calcium ions, larger networks formed when using highly viscous alginates such as LVG and S-alginate (145 and $132 \mathrm{mPa}$ ) than when using less viscous LVM (21 mPa) (Fig. 2). The differences in the magnitude of swelling between G-enriched (LVG) and M-enriched (LVM) alginates could be explained by the number of gelling points and their distribution in the primary alginate sequence and by the viscosity of alginates. Indeed, the affinity to bind $\mathrm{Ca}^{2+}$ increases with a greater number of G-blocks present in the polymer. ${ }^{6}$ On the other hand, alginate viscosity is proportional to polysaccharide chain length, and high-viscosity alginates can form larger hydrogels because of the higher probability of crosslinking of the polysaccharide chains and physical entanglement.

The dissociation constants for mannuronic and guluronic acid monomers are 3.38 and 3.65 , respectively. In aqueous solutions with $\mathrm{pH} 5-9$, alginate behaves as a polyanion because carboxylic groups in sodium alginate are fully dissociated. ${ }^{7}$ In agreement with this fact, we found that the Ca-alginate hydrogel's swelling profile and the minimum gel-forming concentration of calcium ions were not influenced by the $\mathrm{pH}$ value (5.5 or 7.4) during the crosslinking (Figs. 2 and 3).

\section{Swelling of Ca-alginate $\mathrm{NaCl}_{\text {hydrogels in aqueous }}$ $\mathrm{CaCl}_{2}$ solution}

Like Ca-alginate hydrogels, hydrogels generated in the presence of $\mathrm{NaCl}(150 \mathrm{mM}, \mathrm{Ca}$-alginate $\mathrm{NaCl})$ displayed nonlinear swelling profiles in solutions with $\mathrm{pH}$ values of 5.5 (not shown) and 7.4, and a decrease in the $\mathrm{CaCl}_{2}$ concentration to below $4 \mathrm{mM}$ was accompanied by a rapid increase in hydrogel mass (Fig. 3). At a constant concentration of $\mathrm{CaCl}_{2}$, the Ca-alginate $\mathrm{NaCl}$ hydrogel's mass was proportional to the sol volume and concentration of alginate in the sol (Fig. 1a, b). $\mathrm{Na}^{+}$ions do not have any specific binding sites within the alginate, but interact electrostatically with the negatively charged carboxylic groups of the polysaccharide. ${ }^{19}$ We observed that at a low degree of crosslinking $\left(\leq 4 \mathrm{mM}\right.$ of $\mathrm{CaCl}_{2}$ ), exogenous $\mathrm{Na}^{+}$ensures the generation of less swollen hydrogels (Fig. 3) and shifts the minimum gel-forming concentration of $\mathrm{Ca}^{2+}$ ions toward higher $\mathrm{Ca}^{2+}$ concentrations for G-enriched alginates $(1.4$ and $1.6 \mathrm{mM}$ of $\mathrm{CaCl}_{2}$ in S-alginate and LVG, respectively). Thus, when a high $\mathrm{Na}^{+} / \mathrm{Ca}^{2+}$ ratio exists, $\mathrm{Na}^{+}$could inhibit some Genriched sequences in the primary alginate structure from being crosslinked by $\mathrm{Ca}^{2+}$, but does not alter the fundamental principal of hydrogel formation with $\mathrm{Ca}^{2+}$ $\left(\mathrm{CaCl}_{2} \leq 10 \mathrm{mM}\right)$. Moreover, as we demonstrated below, only strongly swollen Ca-alginate $\mathrm{NaCl}_{\mathrm{Na}}$ hydrogels with the degree of swelling above $66 \%$ supported robust neurite outgrowth in vitro.

\section{Mechanical stability of Ca-alginate $\mathrm{NaCl}_{\text {and instability }}$ of Ca-alginate hydrogels in buffered physiological saline}

Sodium is a constituting ion of every extracellular medium in the body, and it contributes to the high ionic strength of extracellular fluids, including blood plasma and cerebrospinal fluid. Moreover, the $\mathrm{pH}$ value in normal blood and cerebrospinal fluid is tightly regulated between 7.35 and 7.45. ${ }^{49,50}$ To predict how long different in situ prepared hydrogels can maintain their dimensions in the presence of these physiological fluids in vivo (e.g., as implants into injured spinal cord) and subsequently support neural growth and regeneration, we quantified hydrogel disintegration in a buffered physiological saline. Ca-alginate and $\mathrm{Ca}$ alginate $_{\mathrm{NaCl}}$ hydrogels generated in the presence of $2 \mathrm{mM}$ of $\mathrm{CaCl}_{2}$ were immersed in buffered physiological saline (150 mM of $\mathrm{NaCl}, \mathrm{pH} 7.4$ ) supplemented with $2 \mathrm{mM}$ of $\mathrm{CaCl}_{2}$
FIG. 1. Hydrogel volume increases with an increase in (a) the volume of alginate sol at constant alginate concentrations in a sol $(1 \%)$ and (b) the concentration of an alginate in a sol at a constant sol volume of $600 \mu \mathrm{L}$. Hydrogels were generated from dry layers of $\mathrm{S}$-alginate by crosslinking with $2 \mathrm{mM}$ of $\mathrm{CaCl}_{2}$ at $\mathrm{pH} 5.5$ in the absence (Ca-alginate) or in the presence of $150 \mathrm{mM}$ of $\mathrm{NaCl}$ (Caalginate $_{\mathrm{NaCl}}$. Data are represented as means \pm standard deviations.
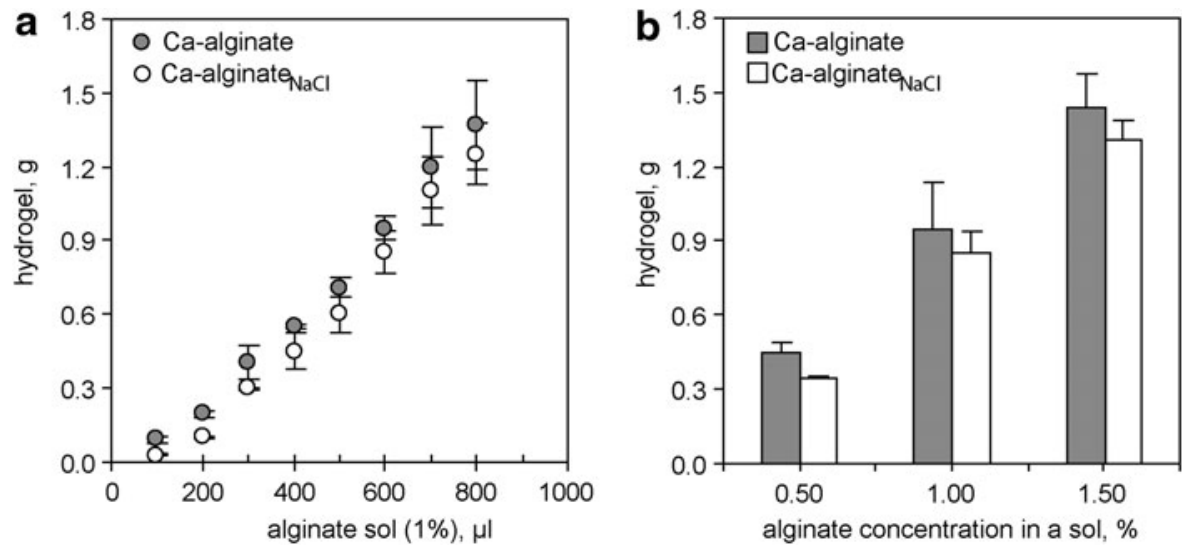

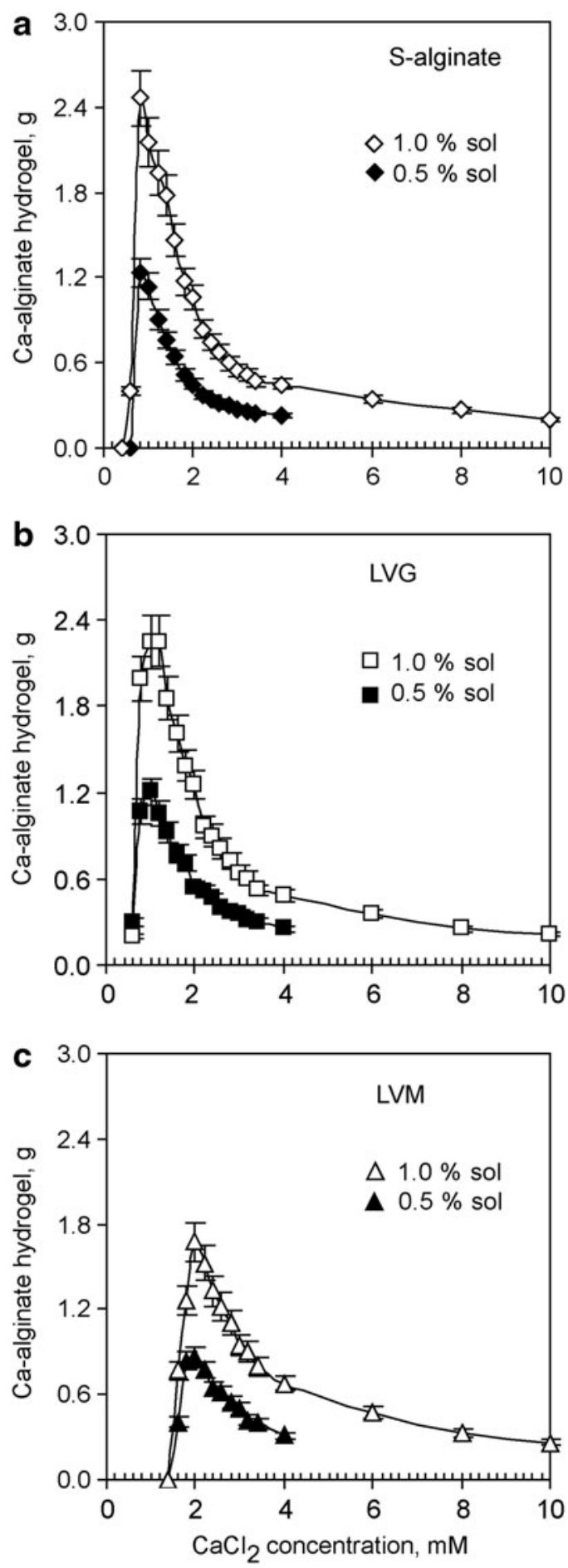

FIG. 2. Swelling of the Ca-alginate hydrogel increases with decreased $\mathrm{CaCl}_{2}$ concentrations in the crosslinking solution. Hydrogels were generated at $\mathrm{pH} 5.5$ by crosslinking dry alginate layers that originated from $600 \mu \mathrm{L}$ of a $1 \%$ sol or $0.5 \%$ sol of (a) S-alginate, (b) guluronic acid rich alginate (LVG), and (c) mannuronic acid rich alginate (LVM). Data are represented as means \pm standard deviations.

and the hydrogel mass was regularly quantified during the subsequent 30 days. Ca-alginate hydrogels derived from LVM completely collapsed, while those derived from LVG and S-alginate lost $\geq 50 \%$ of their mass within the first 30 days (Fig. 4a). Surprisingly, analogous Ca-alginate $\mathrm{NaCl}$
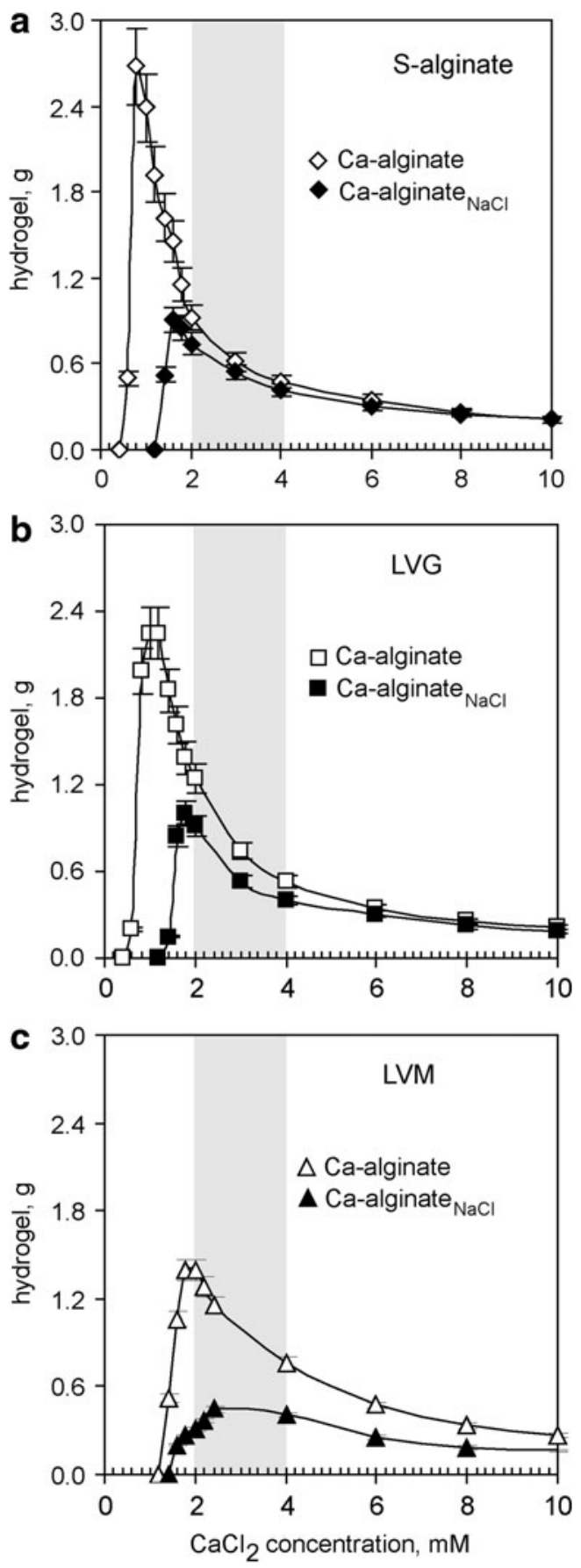

FIG. 3. $\mathrm{NaCl}$ restricts the swelling of hydrogels. Hydrogels were generated at $\mathrm{pH} 7.4$ by crosslinking dry alginate layers with aqueous $\mathrm{CaCl}_{2}$ solutions in the absence (Ca-alginate) or in the presence of $150 \mathrm{mM}$ of $\mathrm{NaCl}$ (Ca-alginate $\mathrm{NaCl})$; alginate layers originated from $600 \mu \mathrm{L}$ of $1 \%$ sol of (a) S-alginate, (b) LVG, and (c) LVM. Data are represented as means \pm standard deviations. The gray background distinguishes $\mathrm{Ca}$-alginate $\mathrm{NaCl}$ hydrogels that support robust neurite outgrowth in vitro.

hydrogels demonstrated long-term mass stability during the entire observation period (Fig. 4b).

\section{Macroscopic morphology of hydrogels}

Rapid binding of calcium ions to alginate produces macroscopically inhomogeneous structures; conversely, slow 
FIG. 4. Ca-alginate $\mathrm{NaCl}_{\mathrm{N}}$ hydrogels demonstrate prolonged volume stability in buffered physiological saline. Ca-alginate and Ca-alginate $\mathrm{NaCl}$ hydrogels were generated at $\mathrm{pH} 5.5$ from dry alginate layers in the presence of $2 \mathrm{mM}$ of $\mathrm{CaCl}_{2}$ (a) in the absence or (b) in the presence of $150 \mathrm{mM}$ of $\mathrm{NaCl}$ and were then incubated in buffered physiological saline $(150 \mathrm{mM}$ of $\mathrm{NaCl}$ at $\mathrm{pH} 7.4$ and $2 \mathrm{mM}$ of $\mathrm{CaCl}_{2}$ ) for 1,10 , and 30 days. Alginate layers were derived from $600 \mu \mathrm{L}$ of a $1 \%$ sol of S-alginate, LVG, and LVM. Data are represented as means \pm standard deviations.
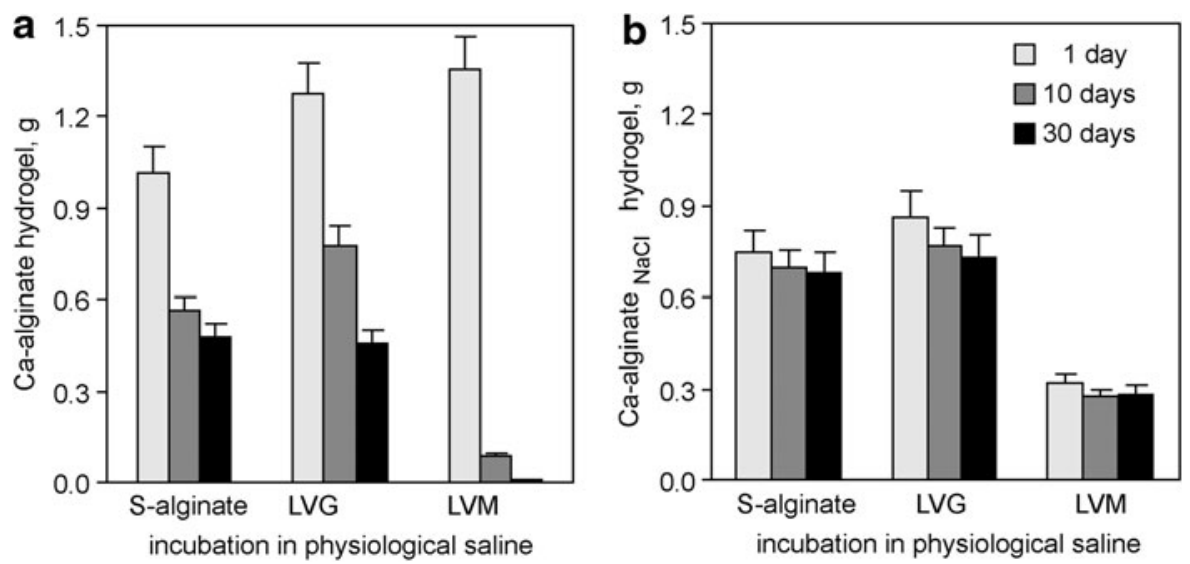

gelation kinetics, which commonly occur in the presence of components that compete with alginate for $\mathrm{Ca}^{2+}$ complexation such as oligoguluronates and EDTA, lead to more homogeneous gels. ${ }^{12,51}$ We noticed remarkable differences in the surface profiles between $\mathrm{Ca}$-alginate $\mathrm{NaCl}_{\mathrm{Na}}$ and analogous Ca-alginate hydrogels. Many of the $\mathrm{Ca}$-alginate $\mathrm{NaCl}_{\mathrm{Na}}$ hydrogels had a smooth and uniform surface, whereas Ca-alginate gels had ruffles and creases of irregular shape and pattern (Fig. 5). The differences in gel appearance were independent of alginate type and became more apparent in gels generated with solutions containing $\leq 3 \mathrm{mM}$ of $\mathrm{CaCl}_{2}$ (Fig. 5f, g). Thus, at a high $\mathrm{Na}^{+} / \mathrm{Ca}^{2+}$ ratio, $\mathrm{Na}^{+}$could delay $\mathrm{Ca}^{2+}$-mediated chain association, which optimizes the spatial organization of the alginate network.

\section{Rheological characterization of Ca-alginate $\mathrm{NaCl}$ hydrogels}

We carried out oscillatory shear measurements in a rheometer and quantified the stiffness of the Ca-alginate $\mathrm{NaCl}$ hydrogels. The stiffness of all tested hydrogels increased with higher levels of $\mathrm{Ca}^{2+}$ in the crosslinking solution. In addition, LVM-derived gels were softer than analogous S-alginate- and LVG-derived gels (Fig. 6). For example, the average stiffness of S-alginate- or LVM-derived Caalginate $_{\mathrm{NaCl}}$ hydrogels formed in the presence of 2, 4, 8, and $10 \mathrm{mM}$ of $\mathrm{CaCl}_{2}$ were $0.011,1.470,3.665$, and $19.230 \mathrm{kPa}$ (S-alginate) and $0.025,0.622,3.085$, and $7.356 \mathrm{kPa}$ (LVM), respectively.

\section{Neurons rapidly extend neurite on soft $\mathrm{Ca}_{\text {-alginate }} \mathrm{NaCl}$ hydrogels}

Neurons have an intrinsic capacity to extend neurite on surfaces they can adhere to. Previously, we described that neurons extend neurite on soft alginate hydrogels prepared with $2 \mathrm{mM}$ of $\mathrm{Ca}^{2+}$, but gelation with $10 \mathrm{mM}$ of $\mathrm{Ca}^{2+}$ resulted in a stiff and nonadhesive hydrogel; this change was attributed to increased tightness of the alginate network. ${ }^{29}$

\section{Ca-alginate hyrogels}
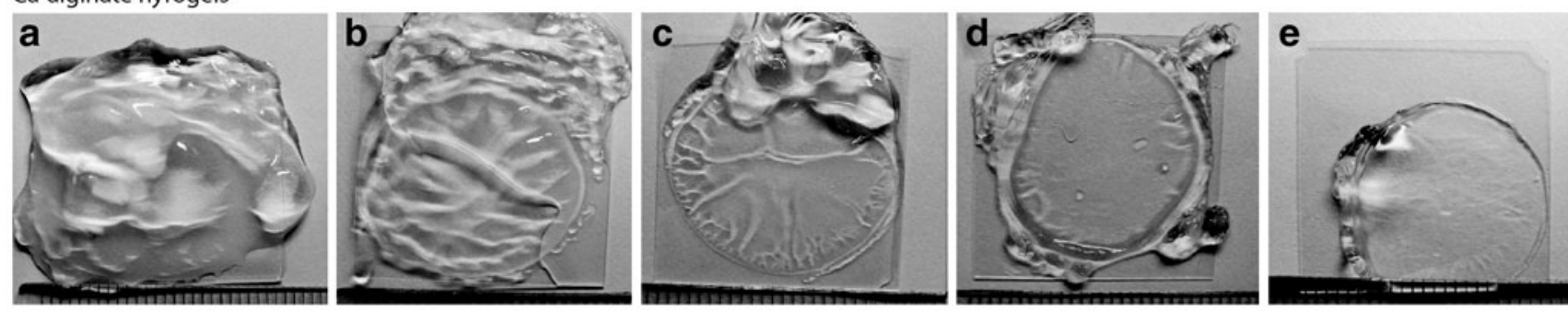

Ca-alginate $_{\mathrm{NaCl}}$ hydrogels

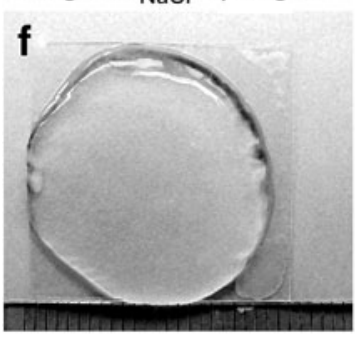

$2 \mathrm{mM}$

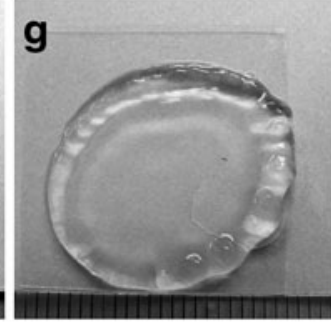

$3 \mathrm{mM}$

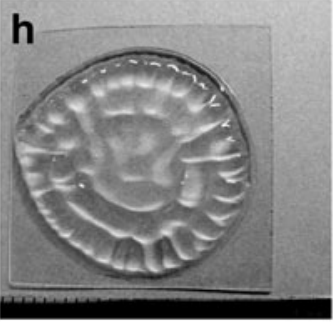

$4 \mathrm{mM}$

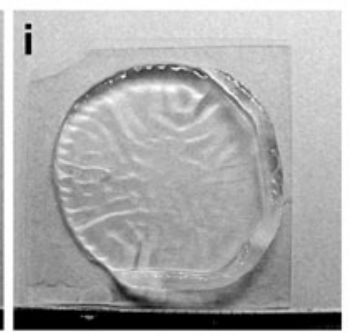

$6 \mathrm{mM}$

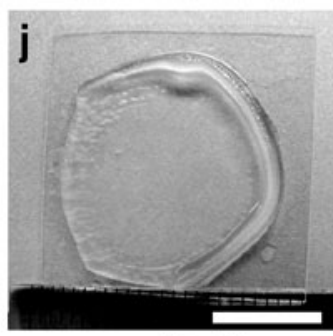

$10 \mathrm{mM}$

concentration of $\mathrm{CaCl}_{2}$ in a cross-linking solution

FIG. 5. Phase-contrast images of Ca-alginate and Ca-alginate $\mathrm{NaCl}_{\mathrm{Cl}}$ hydrogels. Hydrogels were generated at $\mathrm{pH} 7.4$ by crosslinking dry alginate layers of S-alginate with $2-10 \mathrm{mM}$ of aqueous $\mathrm{CaCl}_{2}$ solutions (a-e) in the absence or (f-j) in the presence of $150 \mathrm{mM}$ of $\mathrm{NaCl}$. Alginate layers were derived from $600 \mu \mathrm{L}$ of a $1 \% \mathrm{~S}$-alginate sol. The scale bar is $1 \mathrm{~cm}$. 

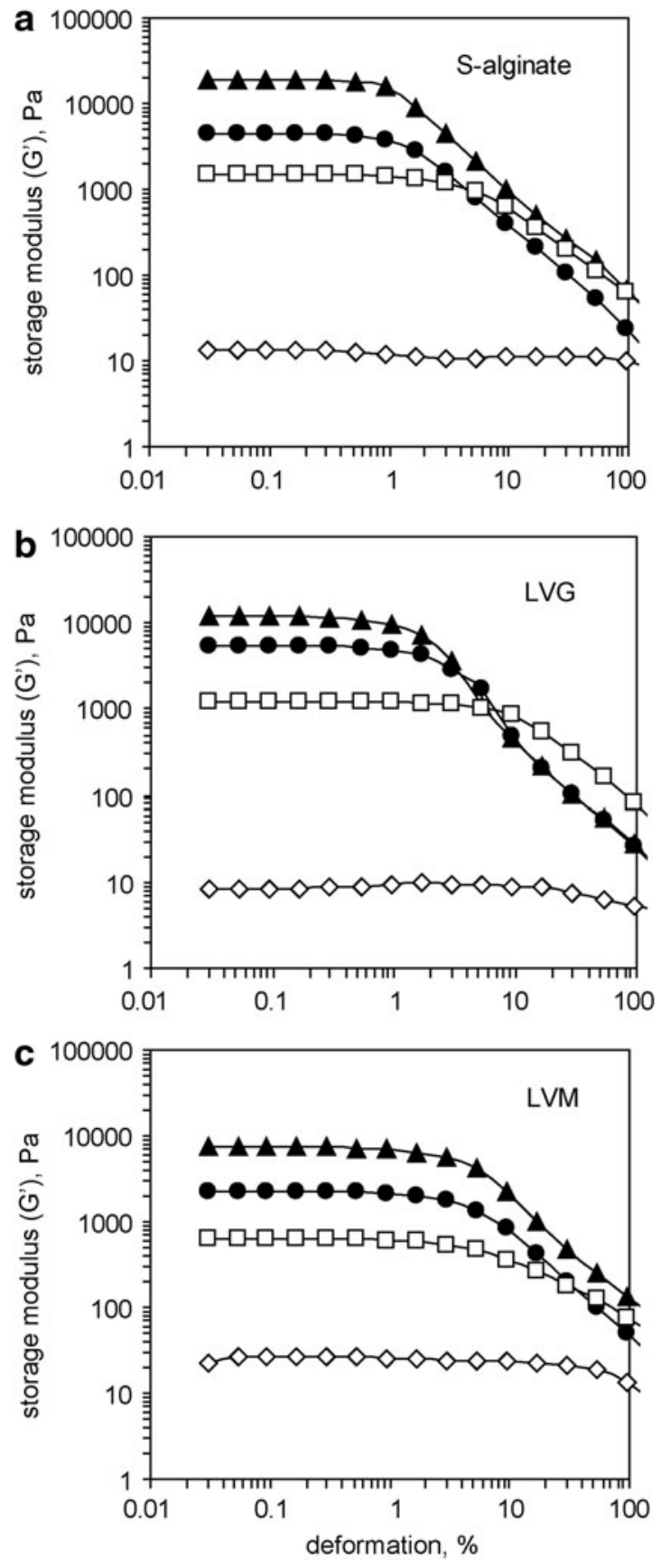

FIG. 6. Increase in the storage modulus $\left(\mathrm{G}^{\prime}\right)$ of a Ca-alginate $_{\mathrm{NaCl}}$ hydrogel correlates with an increase in the concentration of $\mathrm{CaCl}_{2}$. Hydrogels were generated at $\mathrm{pH} 5.5$ by crosslinking dry alginate layers of (a) S-alginate, (b) LVG, and (c) LVM with $(\diamond) 2 \mathrm{mM},(\square) 4 \mathrm{mM},(\bigcirc) 6 \mathrm{mM}$, and $(\boldsymbol{\Delta}) 10 \mathrm{mM}$ of aqueous $\mathrm{CaCl}_{2}$ solution in the presence of $150 \mathrm{mM} \mathrm{NaCl}$. Measurements were performed at $37^{\circ} \mathrm{C}$.

We tested whether Ca-alginate ${ }_{\mathrm{NaCl}}$ hydrogels are still capable of promoting neural adhesion and growth under growth factor-free conditions and without serum. An array of hydrogels were generated from LVM, LVG, and S-alginate; crosslinking was performed in the presence of a constant concentration of $\mathrm{NaCl}(150 \mathrm{mM})$ and different concentrations of $\mathrm{CaCl}_{2}$ (i.e., 2, 4, 6, 8, or $10 \mathrm{mM}$ ) at $\mathrm{pH} 5.5$ or 7.4 .
As we reported previously, the ability of a soft alginate hydrogel to promote neurite extension did not depend on the cell culture system because two-dimensional (2D) adherent monolayers of neurons and 3D neural spheroids produced identical results. ${ }^{29}$ Thus, 3D spheroids were chosen for the cell culture experiments in this study. Spheroids consisted of living cells, which neither accumulated trypan blue dye nor contained fragmented nuclei (data not shown). Three hours after being plated on soft $\mathrm{Ca}$-alginate $\mathrm{NaCl}_{\mathrm{Na}}$ hydrogels (S-alginate, LVG, and LVM gelled with $2 \mathrm{mM}$ of $\mathrm{CaCl}_{2}$ ), multiple neurite extended in all directions and away from the center of the spheroids. The spheroid-derived neurite expressed the neural markers MAP2 and $\beta$-tubulin III (Fig. 7a, e, i and b, f, j) and developed clearly defined growth cones (Supplementary Fig. S1; Supplementary Data are available online at www.liebertpub.com/tec). Growth cone migration elongates neurite, while growth cone splitting creates a branch point resulting in two or more branches. Neurite elongation prevailed over neurite splitting on soft Ca-alginate ${ }_{\mathrm{NaCl}}$ hydrogels since vast majority of neurite (Supplementary Fig. S1a), including MAP2-labeled dendrites (Fig. 7a, e, i) did not branch. Neurite predominantly extended from the area of the spheroid that was in direct contact with the underlying hydrogel. Neurite growth was detected on the surface and in the entire hydrogel volume, gentle shaking could not detach the neurite or the neurite-bearing spheroids. Average distance of neurite extension from spheroids was measured $48 \mathrm{~h}$ after plating of spheroids on top of hydrogels and corresponded to $261 \pm 120,277 \pm 126$, and $312 \pm 135 \mu \mathrm{m}$ on Salginate, LVG, and LVM Ca-alginate $\mathrm{NaCl}_{\mathrm{N}}$ hydrogels generated in the presence of $2 \mathrm{mM}$ of $\mathrm{CaCl}_{2}$, respectively. The proportion of neurite-bearing spheroids on top of S-alginate, LVG, and LVM Ca-alginate $\mathrm{NaCl}$ hydrogels generated in the presence of $2 \mathrm{mM}$ of $\mathrm{CaCl}_{2}$ was $80 \%, 83 \%$, and $93 \%$, respectively, but only $18 \%, 21 \%$, and $22 \%$ on analogous hydrogels prepared in the presence of $4 \mathrm{mM}$ of $\mathrm{CaCl}_{2}$. Gelation with $\geq 6 \mathrm{mM}$ of $\mathrm{CaCl}_{2}$ abolished the attachment of spheroids to the hydrogels and, consequently, eliminated neurite extension (Fig. 7c, d, g, h, k, l). Unlike the importance of calcium concentrations in a crosslinking solution, the $\mathrm{pH}$ values during alginate gelation (5.5 or 7.4) had no influence on spheroid attachment and neurite growth on Ca-alginate $\mathrm{NaCl}$ hydrogels during subsequent cultivation. Spheroid-derived neurite continued to elongate and formed a 3D meshwork by 2 weeks in vitro and express MAP2 and Tau- 1 that label dendrites and axons, respectively (Supplementary Fig. S1b, c).

In agreement with data in the literature, we observed that multiple nestin- and GFAP-labeled cells migrated from the spheroids on poly-l-lysine-coated surfaces to form an adherent 2D cell monolayer (not shown). In contrast, spheroids preserved their 3D shape on alginate hydrogels, and only neurons extended neurite on the top of the soft hydrogel (Fig. 7a, b, e, f, i, j). Unlike neurons, GFAP-positive cells did not extend their processes outside spheroids neither on soft nor on stiff Ca-alginate $\mathrm{NaCl}$ hydrogels.

Since soft Ca-alginate $\mathrm{NaCl}$ hydrogels can be shaped to take any form or size and do not collapse during gentle mechanical treatment, they can be implanted in vivo by direct placing of a piece of hydrogel into a tissue lesion (e.g., lesion formed after traumatic spinal cord or brain injury). Biocompatible, soft Ca-alginate $\mathrm{NaCl}_{\mathrm{Cl}}$ hydrogels promote neural growth and could be tested in the future as neural bridges in vivo. 

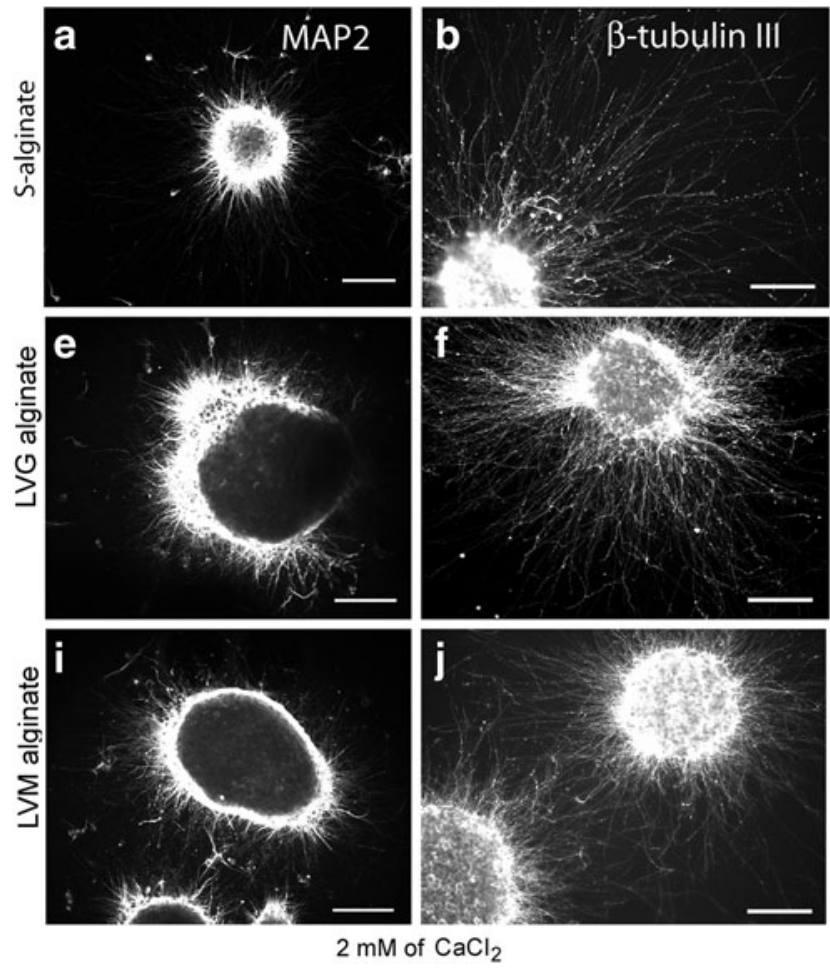
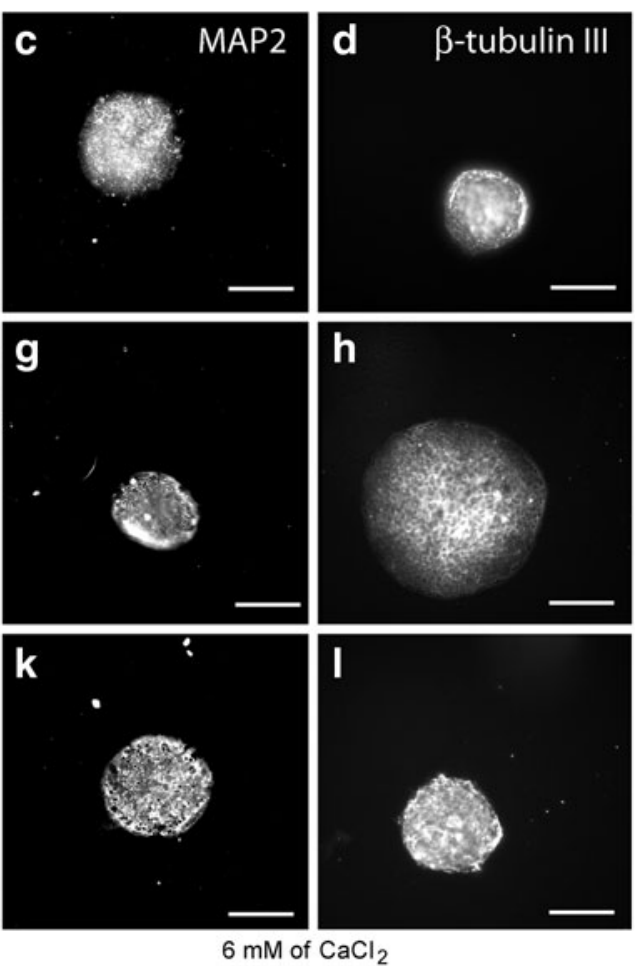

FIG. 7. Soft Ca-alginate $\mathrm{NaCl}$ hydrogels support neurite outgrowth from primary cortical neurons. Fluorescence images show $(\mathbf{a}, \mathbf{c}, \mathbf{e}, \mathbf{g}, \mathbf{i}, \mathbf{k})$ MAP2 and $\mathbf{( b}, \mathbf{d}, \mathbf{f}, \mathbf{h}, \mathbf{j}, \mathbf{1}) \beta$-tubulin III antibody labeling of rat neural three-dimensional spheroids cultured on top of Ca-alginate $\mathrm{NaCl}$ hydrogels for $48 \mathrm{~h}$. Ca-alginate ${ }_{\mathrm{NaCl}}$ hydrogels were generated at $\mathrm{pH} 7.4$ by crosslinking of dry layers of (a-d) S-alginate, (e-h) LVG, or (i-l) LVM alginates with $2 \mathrm{mM}$ or $6 \mathrm{mM}$ of aqueous $\mathrm{CaCl}_{2}$ in the presence of $150 \mathrm{mM}$ of $\mathrm{NaCl}$. The $\beta$-tubulin III antibody labels neuronal bodies and all of the neurite, whereas the MAP2 antibody labels neuronal bodies and dendrites. Fluorescence images in the panels $(\mathbf{a}, \mathbf{e}, \mathbf{i})$ are maximum intensity projection of confocal images obtained from $12-\mu \mathrm{m}$-thick Z-stacks. Secondary antibodies were labeled with the fluorescence dye Alexa Fluor- 488 . The scale bar is $100 \mu \mathrm{m}$.

\section{Discussion}

This study describes soft Ca-alginate $\mathrm{NaCl}_{\mathrm{C}}$ hydrogels as stable 3D matrices with high adhesiveness to neural cells. Within a $\mathrm{pH}$ range that support dissociation of sodium alginate in aqueous solutions, fluctuations in the $\mathrm{pH}$ or ionic strength of the solution and drying of the alginates did not affect neural growth on/within the hydrogel, but gelation in the presence of $\mathrm{NaCl}$ enabled the generation of mechanically stable and soft 3D matrices with mechanical compliance close to brain tissue $(\leq 1.5 \mathrm{kPa})$ that could be tested in the future as neural bridges in vivo. ${ }^{52-54}$

Mechanical compliance of the substrate determines many aspects of cellular behavior, cell morphology, and gene expression. ${ }^{27,55}$ We previously demonstrated that soft, but not stiff alginate hydrogels were able to create an adhesive matrix for primary neurons. Now, we have shown that gelation in the presence of $\mathrm{NaCl}$ enhanced the mechanical stability of soft hydrogels, but did not alter the capacity of the resulting hydrogels to support neural growth. As described for pure Ca-alginate hydrogels, neurons prefer soft over stiff substrates; for example, the soft $\mathrm{Ca}$-alginate $\mathrm{NaCl}_{\mathrm{Na}}$ hydrogels with elastic moduli between $0.01-1.5 \mathrm{kPa}$ supported neurite extensions, while neurons were unable to adhere or spread neurites onto stiff $\mathrm{Ca}$-alginate $\mathrm{NaCl}_{\mathrm{Na}}$ hydrogels, which have elastic moduli above $3 \mathrm{kPa}$.

There is strong auto-cooperative binding of calcium and other di- or multivalent cations by the alginate polysaccha- ride chains in the gel state. ${ }^{6}$ Subsequently, our in vitro neurite outgrowth assay revealed a sharp and noncontinuous transition from adhesive to nonadhesive states for Ca-alginate $\mathrm{NaCl}_{\mathrm{N}}$ hydrogels that was observed between 4 and $6 \mathrm{mM}$ of $\mathrm{CaCl}_{2}$; these qualitative changes were $\mathrm{pH}$ independent and were detected in hydrogels derived from both G-enriched and M-enriched alginates with viscosities ranging from 21 to $145 \mathrm{mPa}$.

Polymers behave differently on surfaces than in solutions. ${ }^{15,16}$ Nevertheless, our results obtained for hydrogels derived from surface-attached alginate layers are largely in agreement with the egg-box model, which was developed for alginate hydrogels in general. We observed that (1) the swelling profiles and stiffnesses of hydrogels fabricated in the presence or absence of $\mathrm{NaCl}$ were controlled by the concentration of $\mathrm{Ca}^{2+}$ and (2) high-viscosity G-enriched alginates required less $\mathrm{Ca}^{2+}$ to form a gel and eventually created larger networks than low-viscosity M-enriched alginates. Alginate concentrations directly influenced the hydrogel mass, but had no noticeable effects on the hydrogel swelling profile; therefore, manipulation of the amount of alginate in a layer could be used to fine tune the hydrogel's dimensions (i.e., to generate a thin matrix to culture neurons or a thick scaffold for implantation in vivo).

The acidic form of alginate is not water soluble, but its sodium salt is. In water, sodium alginate dissociates into negatively charged polymer chains, and mobile sodium ions that form a loosely bound counterion cloud around negative 
charges assure the polymer's water solubility and cause a decrease in intrachain repulsion. Depending on the charge distribution along the chain, polymers could exist either in globular or persistent configurations. Subsequently, hydrogels formed by the association of globular polymer chains occupy more space, while hydrogels formed by persistent polymers are more compact. Additionally, slow gelation kinetics result in macroscopically homogeneous alginate gels. ${ }^{12,15}$ Thus, the macroscopic homogeneity and compactness of Ca-alginate $\mathrm{NaCl}$ hydrogels suggest that exogenous $\mathrm{Na}^{+}$could enable slow gelation kinetics and optimize the spatial organization of an alginate network.

One $\mathrm{Ca}^{2+}$ ion binds up to four guluronic acid residues. ${ }^{21}$ In firmly connected, soft Ca-alginate hydrogels (e.g., in hydrogels derived from $1 \% \mathrm{LVG}$ sol and $2 \mathrm{mM}$ of $\mathrm{CaCl}_{2}$, where $\sim 12 \%$ of the $G$ residues have the potential to be crosslinked), the number of endogenous $\mathrm{Na}^{+}$counterions are not sufficient to neutralize the negative charges on the polysaccharide chains, and repulsion between non-cross-linked sequences results in the formation of extremely swollen hydrogels. After immersion of such soft Ca-alginate hydrogels into physiological saline, exogenous $\mathrm{Na}^{+}$ions penetrate into the hydrogel and, presumably, reduce intrachain repulsion to trigger global 3D changes in the entire network and leakage of $\mathrm{Ca}^{2+}$ ions from gelling sites, which lead to the eventual collapse of the hydrogel. In contrast, soft neurite-supportive Ca-alginate $\mathrm{NaCl}_{\mathrm{Na}}$ hydrogels did not collapse after infiltration of exogenous $\mathrm{Na}^{+}$and maintained their mass and volume after immersion in buffered physiological saline, which makes them interesting for in vivo applications.

Polysaccharides (i.e., sugars) decorate proteins within the ECM and have been found to influence cell migration, axonal guidance, synapse development, and functioning. ${ }^{56,57}$ Most recently, wobble oligosaccharide motifs of chondroitin sulfate/dermatan sulfate proteoglycans had been demonstrated to induce signaling pathways that are essential for the proliferation, self-renewal, and cell lineage commitment of neural stem cells. ${ }^{58}$ Although stiff alginate hydrogels were described as an inert matrix, alginate-derived oligosaccharides have been reported to costimulate growth factormediated proliferation, migration, and adhesion of endothelial cells, keratinocytes, and skin fibroblasts in vitro; ${ }^{59-61}$ cytokine production by RAW264.7 cells; ${ }^{62}$ and phagocytic activity of peritoneal monocytes. ${ }^{63}$ The density of substrateimmobilized signaling molecules is crucial to initiate extracellular signaling events that lead to cell differentiation, adhesion, growth, and migration, and this must be considered during scaffold designing. ${ }^{64,65}$ In light of these reports, we hypothesize that firmly crosslinked alginate networks (and, therefore, soft hydrogels) could create a matrix with a high density of immobilized, adhesion-promoting carbohydrate sequences.

Identification of the molecular mechanisms involved in neural growth on alginate matrices could provide valuable information for regenerative medicine and open new perspectives on using alginate polysaccharides for the functionalization of nonadhesive matrices.

\section{Acknowledgments}

This study was funded by the German Research Foundation (DFG).
The authors wish to acknowledge Prof. Helmut Kettenmann from Max-Delbrück-Center for Molecular Medicine Berlin-Buch, Berlin, Germany, for fruitful discussions, Fabian Luthardt from the Fraunhofer Institute for Ceramic Technologies and Systems (IKTS), Dresden, Germany, for assistance with the rheological measurements, and Dr. Komber from Leibniz Institute of Polymer Research, Dresden, Germany, for ${ }^{1} \mathrm{H}-\mathrm{NMR}$ spectroscopy.

\section{Disclosure Statement}

No competing financial interests exist.

\section{References}

1. Straley, K.S., Foo, C.W., and Heilshorn, S.C. Biomaterial design strategies for the treatment of spinal cord injuries. J Neurotrauma 27, 1, 2010.

2. Wang, S., and Cai, L. Polymer gel system for nerve repair and regeneration. In: Kulshrestha, A., ed. Chapter 3 in Biomaterials, ACS Symposium Series. Washington, DC: American Chemical Society, 2010, pp. 43-63.

3. Li, G.N., and Hoffman-Kim, D. Tissue-engineered platforms of axon guidance. Tissue Eng Part B Rev 14, 33, 2008.

4. Subramanian, A., Krishnan, U.M., and Sethuraman, S. Development of biomaterial scaffold for nerve tissue engineering: biomaterial mediated neural regeneration. J Biomed Sci 16, 108, 2009.

5. Haug, A., and Larsen, B. Biosynthesis of alginate: Part II. Polymannuronic acid C-5-epimerase from Azotobacter vinelandii (Lipman). Carbohydr Res 17, 297, 1971.

6. Smidsrød, O., Glover, R.M., and Whittington, S.G. The relative extension of alginates having different chemical composition. Carbohydr Res 27, 107, 1973.

7. Draget, K.I., Smidsrød, O., and Skjåk-Braek, G. Alginates from algae. In: Steinbüchel, A., and Rhee, S.K., eds. Polysaccharides and Polyamides in the Food Industry. Properties, Production, and Patents. Weinheim: WILEY-VCH, 2005, pp. 1-30.

8. Evans, L.R., and Linker, A. Production and characterization of the slime polysaccharide of Pseudomonas aeruginosa. J Bacteriol 116, 915, 1973.

9. Panikkar, R., and Brasch, D.J. Composition and block structure of alginates from New Zealand brown seaweeds. Carbohydr Res 293, 119, 1996.

10. Morris, E., Rees, D., Thom, D., and Boyd, J. Chiroptical and stoichiometric evidence of a specific, primary dimerisation process in alginate gelation. J Carbohydr Res 66, 145, 1978.

11. Grant, G., Morris, E., Rees, D., Smith, P., and Thom, D. Biological interactions between polysaccharides and divalent cations: the egg-box model. FEBS Lett 32, 195, 1973.

12. Jorgensen, T.E., Sletmoen, M., Draget, K.I., and Stokke, B.T. Influence of oligoguluronates on alginate gelation, kinetics, and polymer organization. Biomacromolecules 8, 2388, 2007.

13. Rees, D.A. Polysaccharide shapes and their interactionssome recent advances. Pure Appl Chem 53, 1, 1981.

14. Stokke, B.T., Smidsrød, O., Bruheim, P., and Skjåk-Braek, G. Distribution of uronate residues in alginate chains in relation to alginate gelling properties. Macromolecules 24, 4637, 1991.

15. Netz, R.R., and Andelman, D. Polyelectrolytes in solution and at surfaces. In: Urbakh, M., and Giladi, E., eds. Encyclopedia of Electrochemistry. Weinheim: Wiley-VCH, 2002, pp. 282-322.

16. Dobrynin, A.V., and Rubinstein, M. Theory of polyelectrolytes in solutions and at surfaces. Prog Polym Sci 30, 1049, 2005. 
17. LeRoux, M.A., Guilak, F., and Setton, L.A. Compressive and shear properties of alginate gel: effects of sodium ions and alginate concentration. J Biomed Mater Res 47, 46, 1999.

18. Martinsen, A., Skjak-Braek, G., and Smidsrod, O. Alginate as immobilization material: I. Correlation between chemical and physical properties of alginate gel beads. Biotechnol Bioeng 33, 79, 1989.

19. Draget, K.I., Steinsvag, K., Onsoyen, E., and Smidsrod, O. $\mathrm{Na}-$ and K-alginate; effect on $\mathrm{Ca}^{2+}$-gelation. Carbohydr Polym 35, 1, 1998.

20. Kuo, C.K., and Ma, P.X. Maintaining dimensions and mechanical properties of ionically crosslinked alginate hydrogel scaffolds in vitro. J Biomed Mater Res A 84, 899, 2008.

21. Fang, Y., Al-Assaf, S., Phillips, G.O., Nishinari, K., Funami, T., Williams, P.A., and Li, L. Multiple steps and critical behaviors of the binding of calcium to alginate. J Phys Chem B 111, 2456, 2007.

22. Kuo, C.K., and Ma, P.X. Ionically crosslinked alginate hydrogels as scaffolds for tissue engineering: part 1. Structure, gelation rate and mechanical properties. Biomaterials 22, 511, 2001.

23. Kong, H.J., Smith, M.K., and Mooney, D.J. Designing alginate hydrogels to maintain viability of immobilized cells. Biomaterials 24, 4023, 2003.

24. Birdi, G., Bridson, R.H., Smith, A.M., Bohari, S.P., and Grover, L.M. Modification of alginate degradation properties using orthosilicic acid. J Mech Behav Biomed Mater 6, 181, 2012.

25. Jejurikar, A., Seow, T.X., Lawrie, G., Martin, D., Jayakrishnan, A., and Grøndahl, L. Degradable alginate hydrogels crosslinked by the macromolecular crosslinker alginate dialdehyde. J Mater Chem 22, 9751, 2012.

26. Gattas-Asfura, K.M., and Stabler, C.L. Chemoselective crosslinking and functionalization of alginate via Staudinger ligation. Biomacromolecules 10, 3122, 2009.

27. Discher, D.E., Janmey, P., and Wang, Y.L. Tissue cells feel and respond to the stiffness of their substrate. Science 310, 1139, 2005.

28. Levental, I., Georges, P.C., and Janmey, P.A. Soft biological materials and their impact on cell function. Soft Matter 3, 299, 2007.

29. Matyash, M., Despang, F., Mandal, R., Fiore, D., Gelinsky, M., and Ikonomidou, C. Novel soft alginate hydrogel strongly supports neurite growth and protects neurons against oxidative stress. Tissue Eng Part A 18, 55, 2012.

30. Jiang, F. X., Yurke, B., Schloss, R. S., Firestein, B. L., and Langrana, N. A. Effect of dynamic stiffness of the substrates on neurite outgrowth by using a DNA-crosslinked hydrogel. Tissue Eng Part A 16, 1873, 2010.

31. Koch, D., Rosoff, W.J., Jiang, J., Geller, H.M., and Urbach, J.S. Strength in the periphery: growth cone biomechanics and substrate rigidity response in peripheral and central nervous system neurons. Biophys J 102, 452, 2012.

32. Previtera, M.L., Langhammer, C.G., and Firestein, B.L. Effects of substrate stiffness and cell density on primary hippocampal cultures. J Biosci Bioeng 110, 459, 2010.

33. Jiang, F.X., Yurke, B., Firestein, B.L., and Langrana, N.A. Neurite outgrowth on a DNA crosslinked hydrogel with tunable stiffnesses. Ann Biomed Eng 36, 1565, 2008.

34. Engler, A.J., Sen, S., Sweeney, H.L., and Discher, D.E. Matrix elasticity directs stem cell lineage specification. Cell 126, 677, 2006.

35. Leipzig, N.D., and Shoichet, M.S. The effect of substrate stiffness on adult neural stem cell behavior. Biomaterials 30, 6867, 2009.
36. Saha, K., Keung, A.J., Irwin, E.F., Li, Y., Little, L., Schaffer, D.V., and Healy, K.E. Substrate modulus directs neural stem cell behaviour. Biophys J 95, 4426, 2009.

37. Seidlits, S.K., Khaing, Z.Z., Petersen, R.R., Nickels, J.D., Vanscoy, J.E., Shear, J.B., and Schmidt, C.E. The effects of hyaluronic acid hydrogels with tunable mechanical properties on neural progenitor cell differentiation. Biomaterials 31, 3930, 2010.

38. Novikova, L.N., Mosahebi, A., Wiberg, M., Terenghi, G., Kellerth, J.O., and Novikov, L.N. Alginate hydrogel and matrigel as potential cell carriers for neurotransplantation. J Biomed Mater Res A 77, 242, 2006.

39. Dhoot, N.O., Tobias, C.A., Fischer, I., and Wheatley, M.A. Peptide-modified alginate surfaces as a growth permissive substrate for neurite outgrowth. J Biomed Mater Res A 71, 191, 2004

40. Yamada, Y., Hozumi, K., Katagiri, F., Kikkawa, Y., and Nomizu, M. Biological activity of laminin peptideconjugated alginate and chitosan matrices. Biopolymers 94, 711, 2010.

41. Ohta, M., Suzuki, Y., Chou, H., Ishikawa, N., Suzuki, S., Tanihara, M., Mizushima, Y., Dezawa, M., and Ide, C. Novel heparin/alginate gel combined with basic fibroblast growth factor promotes nerve regeneration in rat sciatic nerve. J Biomed Mater Res A 71, 661, 2004.

42. Suzuki, Y., Tanihara, M., Ohnishi, K., Suzuki, K., Endo, K., and Nishimura, Y. Cat peripheral nerve regeneration across $50 \mathrm{~mm}$ gap repaired with a novel nerve guide composed of freeze-dried alginate gel. Neurosci Lett 259, 75, 1999.

43. Suzuki, Y., Kitaura, M., Wu, S., Kataoka, K., Suzuki, K., Endo, K., Nishimura, Y., and Ide, C. Electrophysiological and horseradish peroxidase-tracing studies of nerve regeneration through alginate-filled gap in adult rat spinal cord. Neurosci Lett 318, 121, 2002.

44. Kataoka, K., Suzuki, Y., Kitada, M., Hashimoto, T., Chou, H., Bai, H., Ohta, M., Wu, S., Suzuki, K., and Ide, C. Alginate enhances elongation of early regenerating axons in spinal cord of young rats. Tissue Eng 10, 493, 2004.

45. Prang, P., Muller, R., Eljaouhari, A., Heckmann, K., Kunz, W., Weber, T., Faber, C., Vroemen, M., Bogdahn, U., and Weidner, N. The promotion of oriented axonal regrowth in the injured spinal cord by alginate-based anisotropic capillary hydrogels. Biomaterials 27, 3560, 2006.

46. Pawar, K., Müller, R., Caioni, M., Prang, P., Bogdahn, U., and Kunz, W. Increasing capillary diameter and the incorporation of gelatin enhance axon outgrowth in alginatebased anisotropic hydrogels. Acta Biomater 7, 2826, 2011.

47. Grasdalen, H., Larsen, B., and Smidsrod, O. A P.M.R. study of the composition and sequence of uronate residues in alginates. Carbohydr Res 68, 23, 1979.

48. Ebert, A.D., McMillan, E.L., and Svendsen, C.N. Isolating, expanding and infecting human and rodent fetal neural progenitor cells. Curr Protoc Stem Cell Biol Chapter 2:Unit 2D.2, 2008.

49. Freund, J., and Kalbitzer, H.R. Physiological buffers for NMR spectroscopy. J Biomol NMR 5, 321, 1995.

50. Pirke, K.M., Wisser, H., and Mertin, J. Die Konzentrationen von Natrium, Kalium, Calcium, Magnesium und Chlorid im Liquor cerebrospinalis und ihre Beziehungen zu den Serumkonzentrationen. Clin Chem Lab Med 10, 462, 1972.

51. Draget, K., Ostgaard, K., and Smidsrod, O. Homogeneous alginate gels-a technical approach. Carbohydr Polym 14, 159,1990

52. Elkin, B.S., Azeloglu, E.U., Costa, K.D., and Morrison, B. Mechanical heterogeneity of the rat hippocampus measured 
by atomic force microscope indentation. J Neurotrauma 24, 812, 2007.

53. Green, M.A., Bilston, L.E., and Sinkus, R. In vivo brain viscoelastic properties measured by magnetic resonance elastography. NMR Biomed 21, 755, 2008.

54. Christ, A.F., Franze, K., Gautier, H., Moshayedi, P., Fawcett, J., Franklin, R.J., Karadottir, R.T., and Guck, J. Mechanical difference between white and gray matter in the rat cerebellum measured by scanning force microscopy. J Biomech 43, 2986, 2010.

55. Solon, J., Levental, I., Sengupta, K., Georges, P.C., and Janmey, P.A. Fibroblast adaptation and stiffness matching to soft elastic substrates. Biophys J 93, 4453, 2007.

56. Rhiner, C., and Hengartner, M.O. Sugar antennae for guidance signals: syndecans and glypicans integrate directional cues for navigating neurons. Sci World J 6, 1024, 2006.

57. Frischknecht, R., and Seidenbecher, C.I. The crosstalk of hyaluronan-based extracellular matrix and synapses. Neuron Glia Biol 4, 249, 2008.

58. Purushothaman, A., Sugahara, K., and Faissner, A. Chondroitin sulfate "wobble motifs" modulate maintenance and differentiation of neural stem cells and their progeny. J Biol Chem 287, 2935, 2012.

59. Kawada, A., Hiura, N., Shiraiwa, M., Tajima, S., Hiruma, M., Hara, K., Ishibashi, A., and Takahara, H. Stimulation of human keratinocyte growth by alginate oligosaccharides, a possible co-factor for epidermal growth factor in cell culture. FEBS Lett 408, 43, 1997.

60. Kawada, A., Hiura, N., Tajima, S., and Takahara, H. Alginate oligosaccharides stimulate VEGF-mediated growth and migration of human endothelial cells. Arch Dermatol Res 291, 542, 1999.

61. Tajima, S., Inoue, H., Kawada, A., Ishibashi, A., Takahara, H., and Hiura, N. Alginate oligosaccharides modulate cell morphology, cell proliferation and collagen expression in human skin fibroblasts in vitro. Arch Dermatol Res 291, 432, 1999.

62. Yamamoto, Y., Kurachi, M., Yamaguchi, K., and Oda, T. Induction of multiple cytokine secretion from RAW264.7 cells by alginate oligosaccharides. Biosci Biotechnol Biochem 71, 238, 2007.

63. Pasquali, P., Zalcman, A., Murtas, S., Adone, R., Brambilla, G., Marianelli, C., Cagiola, M., and Ciuchini, F. In vitro stimulation of murine peritoneal monocytes induced by alginates. Arch Pharm Res 28, 936, 2005.

64. Silva, G.A., Czeisler, C., Niece, K.L., Beniash, E., Harrington, D.A., Kessler, J.A., and Stupp, S.I. Selective differentiation of neural progenitor cells by high-epitope density nanofibers. Science 303, 1352, 2004.

65. Cai, L., Lu, J., Sheen, V., and Wang, S. Optimal poly(L-lysine) grafting density in hydrogels for promoting neural progenitor cell functions. Biomacromolecules 13, 1663, 2012.

Address correspondence to: Marina Matyash, PhD Center for Translational Bone, Joint and Soft Tissue Research University Hospital and Medical Faculty Technische Universität Dresden

Fetscherstrasse 74 13187 Dresden Germany

E-mail: marina_matyash@yahoo.de

Received: April 23, 2013 Accepted: September 16, 2013

Online Publication Date: November 5, 2013 


\section{Supplementary Data}
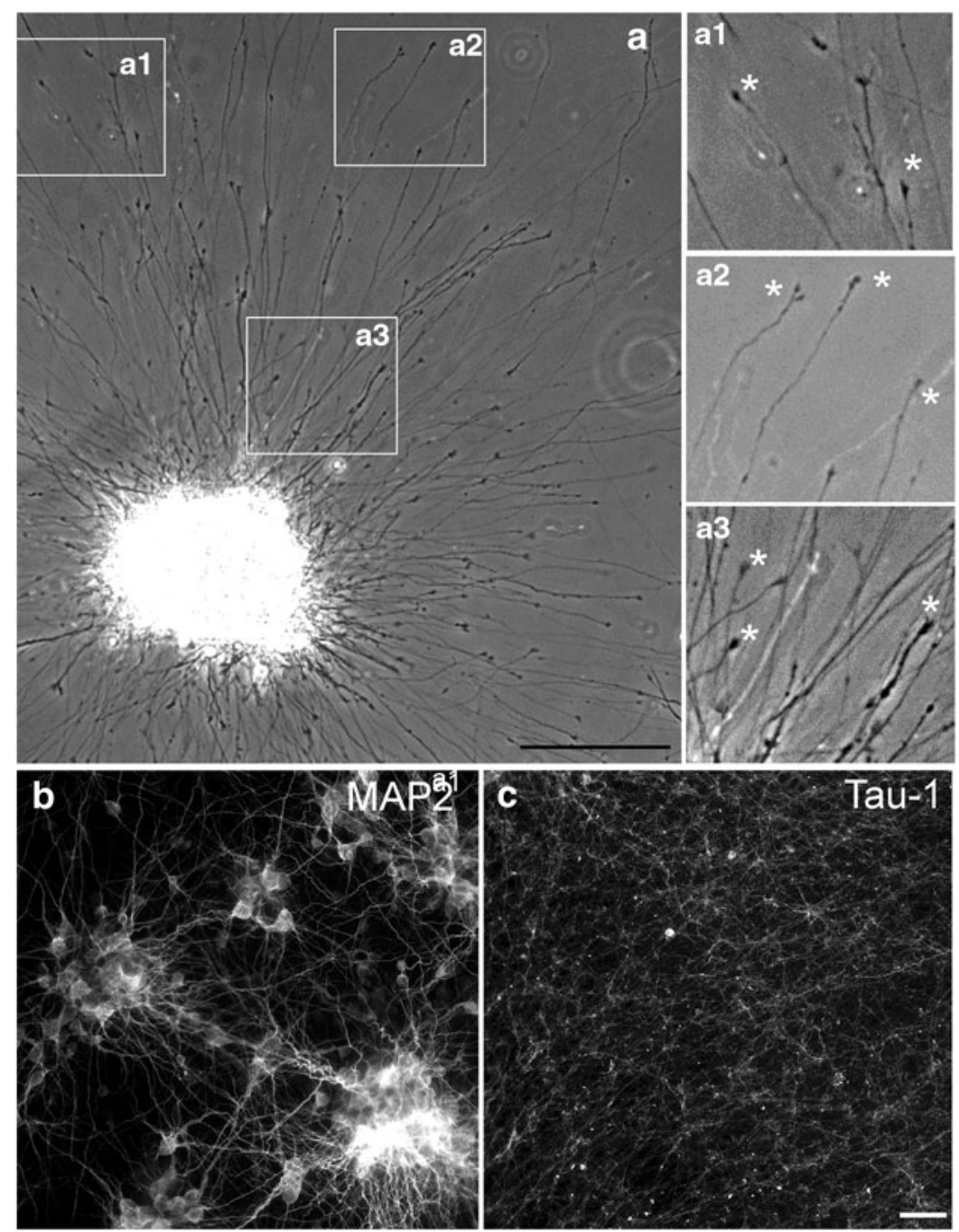

SUPPLEMENTARY FIG. S1. Live images show a rat primary cortical neurite-bearing spheroid cultured for $48 \mathrm{~h}$ on (a) Caalginate $_{\mathrm{NaCl}}$ hydrogel. Images in (a1, a2, a3) are enlarged frames of the corresponding images in (a). Neurite have visible growth cones (marked by ${ }^{*}$ ) on their tips. Spheroid-derived neurite continued to elongate and formed a (b, c) threedimensional meshwork; soft hydrogel supports outgrowth of dendrites and axons. Fluorescence images show (b) MAP2 and (c) Tau-1 antibody-labeling of neurite-bearing spheroids and neurite meshwork on top of Ca-alginate $\mathrm{NaCl}_{\mathrm{Nydrogels}}$ after 2 weeks in vitro. Ca-alginate $\mathrm{NaCl}_{\mathrm{N}}$ hydrogels were generated at $\mathrm{pH} 7.4$ by crosslinking of dry layers of LVM alginate with 2 mM of aqueous $\mathrm{CaCl}_{2}$ in the presence of $150 \mathrm{mM}$ of $\mathrm{NaCl}$. Secondary antibodies were labeled with the fluorescence dye Alexa Fluor-488. The scale bar is $100 \mu \mathrm{m}$. 